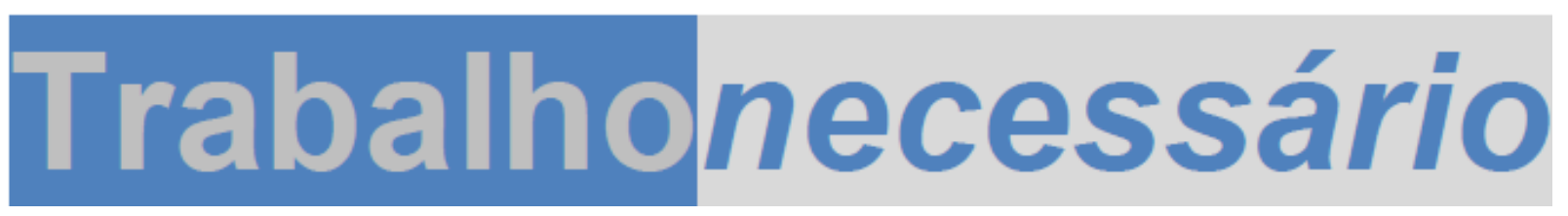

\author{
Issn: 1808 - 799X \\ ano 11, no $16-2013$
}

\title{
O CACS- FUNDEB E A DEFESA DA ESCOLA PÚBLICA- Limites e possibilidades
}

Marco Vinícius Moreira Lamarão ${ }^{1}$

Resumo: Este artigo tem como objetivo sintetizar um balanço acerca da análise do Conselho de Acompanhamento e Controle Social do FUNDEB no Município de Itaboraí no período de 2011-2012. Através de um quadro teórico que parte do materialismo histórico, que busca entender a sociedade através do conflito e da contradição, usa-se e debate-se aqui conceitos como conselhos, Estado Integral, sociedade civil e sociedade política, guerra de posição e de movimento, intelectual, dentre outros. Neste sentido problematiza-se o sentido da proliferação dos conselhos na educação no Brasil, contextualizando-os e investigando as diversas matrizes teóricas que pensaram os conselhos em sua relação com 0 Estado e a sociedade. Desta aproximação, analisa-se o referido objeto através de sua legislação, do acompanhamento das suas reuniões e das suas planilhas contábeis. Partindo da hipótese da existência de uma tensão entre as possibilidades e limites de ação dos trabalhadores da educação no interior deste conselho, busca-se dar conta da seguinte questão central: em que medida e de que forma o CACS-FUNDEB pode ser um instrumento utilizado pelos trabalhadores da educação e demais trabalhadores na construção de uma escola pública, de qualidade, laica, gratuita e emancipatória.

Palavras-chave: conselhos do FUNDEB; Controle Social; gestão democrática

Abstract: This article aims to synthesize a balance regarding the analysis of the "Conselho de Acompanhamento e and Controle Social" of FUNDEB at Itaboraí city between 2011 and 2012. Through a theoretical framework that starts on the historical materialism, that aims to understand the society through the conflict and

\footnotetext{
${ }^{1}$ Aluno do Programa de Pós- graduação em Educação da UFRJ-2011, na linha de Instituições e Políticas Públicas, bolsista CAPES, sob orientação do Prof. Dr. Roberto Leher, onde integra Coletivo de Estudos Marxismo e Educação (COLEMARX). Professor da rede pública Municipal de Itaboraí e diretor de Comunicação e Imprensa no Sindicato Estadual dos Profissionais da EducaçãoItaboraí (SEPE-Ita) e da Secretaria de Assuntos Educacionais e Formação Sindical do SEPE-RJ. E-mail: marcolamarao@gmail.com
}

TrabalhoNecessário - www.uff.br/trabalhonecessario; Ano 11, № 16/2013. 


\section{Trabalhonecessário}

Issn: 1808 - 799X

ano 11, no $16-2013$

contradiction, concepts such advice Integral state, civil society and political society, war of position and movements, intellectual, among others, are used and discussed herein. Therefore, it is problematized debated the meaning of the proliferation of councils on education in Brazil, contextualizing them and investigating the various theoretical frameworks that thought the councils on their relationship with the State and the society. Therefore So, we analyze the object referred object via its legislation, monitoring its meetings and its accounting spreadsheets. Assuming the existence of a tension between the possibilities and limits of action of workers of education within this council is pursued to solve the following question: o which extent and how the CACS-FUNDEB can be a tool used by education workers and other workers in the construction of quality, secular, free and emancipation public school.

Keywords: councils of FUNDEB; Social Control; democratic management; professional development.

\section{Introdução}

O objeto deste artigo é o Conselho de Acompanhamento e Controle Social (CACS) do Fundo de Manutenção e Desenvolvimento da Educação Básica e de Valorização dos Profissionais da Educação (FUNDEB), doravante chamado de CACS-FUNDEB, do Munícipio de Itaboraí- RJ. O referido conselho tem como função primordial o acompanhamento da aplicação dos recursos públicos advindos do FUNDEB, partindo do princípio do "controle social", através da participação de segmentos da sociedade civil.

Nesta análise, busca-se responder algumas questões como: este conselho cumpre- e, se cumpre, em que medida- com sua função de controle social? Como consequência, o conselho contribui para a socialização da politica e a expansão da democracia? Ou, ao contrário, esvazia esta participação ao retirar de alcance do conselho os debates estruturais do financiamento da educação 


\section{Trabalhonecessário}

Issn: 1808 - 799X

ano 11, no $16-2013$

pública reduzindo a ação dos conselheiros - que é política- em uma ação meramente técnica? Ademais, é fornecida aos conselheiros a formação técnica para a realização de suas funções? Estas respostas serão importantes na construção de uma questão central: se o CACS-FUNDEB pode ser um instrumento utilizado pelos trabalhadores da educação e demais na construção de uma escola pública de qualidade, laica e emancipatória.

Organizou-se esta exposição da seguinte forma: inicia-se com um debate conceitual, através de algumas pontuações acerca da Teoria do Estado no materialismo histórico- com especial atenção à obra de Antônio Gramsci- no qual se busca realizar o debate acerca de conceitos como "Estado Integral" (sociedade civil e sociedade política), "hegemonia", "intelectual orgânico", "Estado-educador e conformismo". O recurso a estes conceitos intentam o enfrentamento das questões colocadas pelo neoliberalismo de Terceira Via, ou social liberalismo, corrente de pensamento responsável pela Reforma Gerencial iniciada no governo Fernando Henrique Cardoso (FHC) onde se a elaboração e instituição do Conselho de "controle social" do fundo anterior, o FUNDEB. São estes dois pontos- neoliberalismo da Terceira Via e Reforma Gerencial no governo FHC- os debates seguintes.

Feito o debate sobre a pertinência destes conceitos na realidade brasileira, partiremos para a análise da legislação atinente ao nosso objeto - em nível federal e municipal - para, a seguir, determo-nos em algumas observações extraídas da observação empírica do objeto investigado. Por fim, se conclui buscando responder as questões colocadas. 


\section{Trabalhonecessário}

Issn: 1808 - 799X

ano 11, no $16-2013$

\section{A Teoria marxista do Estado}

A exploração sobre o trabalho ou a expropriação de parcela substancial da riqueza de uma classe sobre outra não é uma característica peculiar do capitalismo. Mas o capitalismo tem uma diferença substancial com relação a outras "formas pré-capitalistas" de produção. Segundo Wood (2003), no capitalismo há total separação entre os mecanismos de apropriação do trabalho alheio das funções "extra econômicas", bem como o fenômeno da alienação da esfera política da esfera econômica. Ou seja, a luta de classes no capitalismo (a exploração classista sobre o trabalho) se encontra, centralmente, na esfera da produção, pois é lá que se concentram os principais instrumentos de expropriação. Emerge, neste cenário, a importância do Estado, que concentraria diversas funções necessárias para a reprodução e o desenvolvimento destas relações de produção "econômicas". Havendo esta separação nítida entre "econômico" e "político", cabe ao Estado, no capitalismo, um papel central e um "caráter público sem precedentes". (WOOD, 2003: 37-43).

Em geral, Marx e Engels, ao analisarem o Estado, mediante o contexto histórico extremamente revolucionário em que viviam (o século XIX), percebiamno através de sua faceta coercitiva/repressora, pois mediante os incipientes instrumento de luta das classe fundamentais do capitalismo, a conservação do poder tinha no binômio Estado-Aparato Coercitivo o seu mais importante instrumento. Através desta perspectiva, puderam formular uma Teoria do Estado e seu caráter classista, afirmando ser este um instrumento de subordinação e tutela de uma maioria por uma minoria. Isto, no contexto filosófico da época, representava a "desfetichização" da aparente "autonomia", "superioridade" ou "neutralidade" do Estado, tão bem representada na filosofia Hegeliana.

Lênin (2007) segue estes indícios, quando enfatiza - em sua análise sobre o Estado - os aspectos coercitivos deste (impostos, prisões, exércitos, fundando o

TrabalhoNecessário - www.uff.br/trabalhonecessario; Ano 11, № 16/2013. 


\section{Trabalhonecessário \\ Issn: 1808 - 799X \\ ano 11, no $16-2013$}

monopólio estatal sobre a coerção), definindo o Estado como "instrumento de exploração da classe oprimida" (LÊNIN,2007; 30). Em outra obra, ressalta a importância das grandes potências para a reprodução do capital monopolista (expressão da fusão entre o capital bancário e o capital industrial) quando estes promovem a "partilha do mundo" e dividem entre as grandes potências europeias (inclua-se: EUA e Japão) extensas regiões territoriais para a exploração econômica e a realização do excedente econômico produzido nos países mais desenvolvidos industrialmente. (LÊNIN, 2012). Não sem conflitos e contradições, esta partilha e a discordância sobre ela é fator fundamental para o entendimento da Primeira Guerra Mundial.

Compreendendo esta limitação histórica dos autores pregressos, Gramsci propõe uma adição a este conceito de Estado, tendo em vista que os autores clássicos não puderam acompanhar o surgimento e a evolução dos grandes sindicatos econômicos e dos partidos de massas, o parlamento eleito por sufrágio universal, etc. Ou seja, as instituições, organizações ou grupos, etc. que produzem política, onde o indivíduo ou grupo social adere de forma voluntária. Deve-se, portanto, repensar

"[O] Conceito de Estado que, habitualmente, é entendido como sociedade política (ou ditadura, ou aparelho coercitivo, para moldar a massa popular segundo o tipo de produção e a economia de um dado momento), e não como um equilíbrio da sociedade política com a sociedade civil (ou hegemonia de um grupo social sobre toda a sociedade nacional exercida através das organizações ditas privadas, como a Igreja, os sindicatos, as escolas, etc.), e é especialmente na sociedade civil que operam os intelectuais" (GRAMSCI, 2011, 267)

Assume-se a "fórmula" apresentada por Gramsci de que o "Estado = sociedade política + sociedade civil, isto é, hegemonia couraçada de coerção" (Idem, ibidem, 269). Duas questões legitimam o tratamento "autônomo" que estas duas esferas têm em Gramsci. A primeira se relaciona com a função que cada uma exerce na tarefa de manter determinada organização social. Através da 


\section{Trabalhonecessário}

Issn: 1808 - 799X

ano 11, no 16 - 2013

sociedade civil os setores dominantes buscam construir sua hegemonia, baseando-se, em geral, no consenso ou direção política, pela adesão individual voluntária; enquanto que, na sociedade política esta dominação é mantida, mormente, através da ditadura ou coerção.

É fundamental dizer que, com a sociedade civil, aquilo que se entende por ideologia, ganha uma base material. E, neste ponto, se afirma a segunda questão que permite tal distinção: estas duas esferas se distinguem por uma materialidade própria e específica. "Em Gramsci, não há hegemonia, direção politica e ideológica, sem o conjunto de organizações materiais que compõem a sociedade civil enquanto esfera específica do ser social." (COUTINHO, 2007, 129). Contudo, havendo esta autonomia relativa entre as duas esferas do Estado, Gramsci não perde de foco a unidade dentre elas e a relação dialética que uma mantém com a outra. Esta é uma disjunção não-orgânica, analítica. Como fenômeno social, na realidade específica, sociedade civil e sociedade política se identificam. O que em Gramsci se afirma é que a sociedade civil é palco privilegiado da luta de classes, com aparelhos privados de hegemonia que servem tanto a crítica da sociedade quanto, mormente, a sua reprodução.

O autor italiano, ao analisar esta nova conformação histórica do Estado, busca formular uma tática revolucionária, pertinente a esta realidade. Refuta, assim, a ideia de "guerra de movimento" ou uma tomada de assalto ao poder, tática adequada para os Estados onde a sociedade civil ainda não se encontra plenamente desenvolvida (Estado do tipo Oriental), cujo ato simbólico teria sido a revolução bolchevique de 1917. Gramsci afirma que, neste novo tipo de Estado (onde a sociedade civil se encontra desenvolvida, os ditos Estados Ocidentais), a tática mais adequada aos trabalhadores na luta de classes seria a "guerra de posição" que consiste na possibilidade dos trabalhadores, gradualmente, conquistarem posições na Sociedade Civil e Sociedade Política ao passo que constroem uma hegemonia própria da sua classe.

TrabalhoNecessário - www.uff.br/trabalhonecessario; Ano 11, № 16/2013. 


\section{Trabalhonecessário}

Issn: 1808 - 799X

ano 11, no $16-2013$

Gramsci, ainda, ressalta o caráter educativo existente em toda relação política, e, com isto, coloca em evidência o caráter conformista do Estado, ou a produção de uma sociabilidade que visa produzir personalidades nas massas afinadas com o desenvolvimento social. Afirma Gramsci (2006:94): "somos conformistas de algum conformismo". O Estado (em especial a escola positivamente, e o direito negativamente) seria "Estado-educador". Pois, a

Tarefa educativa e formativa do Estado ... é sempre o de criar novos e mais elevados tipos de civilização, de adequar a "civilização" e a moralidade das mais amplas massas populares às necessidades do contínuo desenvolvimento do aparelho econômico de produção e, portanto, de elaborar também fisicamente tipos novos de humanidade." (ibid.: 23)

Com isto, dá-se relevo ao papel do conformismo no processo pedagógico (e, portanto, político). Se o Estado, no capitalismo, sob o controle de determinada(s) fração(ões) da burguesia, através tanto da sociedade política, como também da sociedade civil, tem a incumbência de conformar as massas trabalhadoras, às "necessidades do contínuo desenvolvimento do aparelho econômico", elaborando seus aspectos psicológicos e físicos destes, os fazem através dos seus "intelectuais orgânicos". Estes intelectuais tem a tarefa de "organizar a sociedade", ou seja, de tornar universal o projeto da fração de classeou classe - a qual pertence. São orgânicos, pois organizam a visão da classe a qual pertence.

Assim, estes intelectuais buscam construir a hegemonia da sua respectiva classe (ou fração) e, para tanto, precisam estar atento às frações e classes subalternas, suas demandas, buscando produzir uma correlação de forças sempre favorável às necessidades das frações as quais representa, objetivando produzir o consenso. Para isto, podem usar de diversos expedientes de cooptação, seja a um importante dirigente isolado de uma fração ou classe adversárias, seja a um grupo mais numeroso destes a fim de melhor subordinar a 


\section{Trabalhonecessário}

Issn: 1808 - 799X

ano 11, no 16 - 2013

fração de classe ou classe da qual este "novo pessoal" de originou, ou mesmo assumindo de forma subordinada parcelas das demandas das classes subalternas.

Com isto afirmado, cabe nos determos no projeto de sociabilidade em execução pelas frações hegemônicas da classe dominante na atualidade, cuja inspiração é dada pela chamada Terceira Via, que tem nos conselhos de participação da sociedade civil um papel fulcral.

\section{O novo conformismo: o Neoliberalismo de Terceira Via}

O Estado de Bem - Estar social ao longo de boa parte do século XX, seria uma das estratégias de cooptar a classe trabalhadora, pois através das lutas, organizações e reivindicações destes, parcela de suas demandas foi incorporada pelo Estado, que assumiu o compromisso de garantir alguns direitos sociais, ou mesmo o esforço pelo pleno emprego, dando àquela crise histórica (1929) do capitalismo uma resposta satisfatória, afinal, garantia o mais importante, a continuidade do modelo socioeconômico, evitando a adesão de amplos segmentos da classe trabalhadora ao projeto socialista (MELO; 2005).

A crise do petróleo (1973), a reorganização produtiva do trabalho (acumulação flexível, flexibilização das relações, a difusão da microeletrônica, da robótica e da informática, etc.) determinam a necessidade de um novo tipo humano, um novo homem coletivo, em conformidade com estas novas determinações econômicas. Além disso, a precarização das relações de trabalho e das condições de vida de um contingente cada vez maior de trabalhadores leva o capital a redesenhar suas estratégias de obtenção do consenso, no final do século XX. Nisto, o Estado de Bem- Estar também é atingido, graças à crise fiscal de 1982, que estimula a substituição deste pelo Estado Neoliberal.

TrabalhoNecessário - www.uff.br/trabalhonecessario; Ano 11, № 16/2013. 


\section{Trabalhonecessário}

Issn: 1808 - 799X

ano 11, no $16-2013$

A crise fiscal e econômica que atravessava o mundo nesta época faz ganhar força um argumento que tinha perdido fôlego desde a crise de 1929, a ideia de que o Estado é ineficaz graças à sua natureza burocrática e monopolista. O corolário deste raciocínio seria um mercado livre (sem distorções promovidas por qualquer interveniência estatal na economia) como o ideal a atingir. Para isto, era necessário reduzir o tamanho do Estado ao mínimo (downsizing), em especial nas áreas sociais como educação, saúde, previdência e nos chamados setores estratégicos, onde os Estados- Nação tinham como mau hábito manter sob controle, ou mesmo, monopolizar (HAYEK; 1999). A redução de gastos do Estado poderia the dar condições de maior governabilidade, bem como possibilitaria que o mercado, mais eficiente, oferecesse de forma mais barata e mais satisfatória, os direitos sociais.

Os países da América Latina foram, em geral, locus privilegiados para estas reformas que previam medidas concretas como um amplo processo de privatização, setorização de políticas públicas sociais, ataques à direitos adquiridos e às organizações trabalhadoras, legitimação de novos atores sociais (ONG's). Estas reformas tiveram no FMI e no Banco Mundial importantes aparelhos privados de hegemonia. Junto aos empréstimos concedidos por estes bancos aos países endividados, havia a necessidade de se apresentar garantias de pagamento e também de desenvolvimento, o que significava assumir uma série de políticas compensatórias de diminuição da desigualdade e também do "empoderamento" de minorias, no intuito de conferir maior estabilidade aos regimes democráticos participativos, etc. (MELO; 2005).

Contudo, a aplicação destas medidas não logrou o êxito esperado, suscitando reações populares que colocavam em xeque este projeto de sociabilidade (crise do México, crise da Argentina, por exemplo). Seria necessário operar determinados ajustes. Foi neste sentido que a chamada Terceira Via (também denominada de neoliberalismo de Terceira Via) ganha espaço e passa 


\title{
Trabalhonecessário
}

Issn: 1808 - 799X

ano 11, no $16-2013$

a, paulatinamente, direcionar as pautas e os documentos produzidos pelo $\mathrm{FMl}$ e Banco Mundial.

Os intelectuais desta corrente tinham na reforma do Estado um princípio orientador. Caberia ao Estado promover uma sociedade civil ativa, onde seria possível restaurar os laços de solidariedade e a coesão social, assim,

\begin{abstract}
... no âmbito da teorização proposta, a sociedade civil constitui-se em uma instância que possui uma materialidade, uma força própria e portadora de um elevado grau de autonomia e independência do processo histórico. Seria o novo agente histórico por excelência, em lugar das classes sociais polarizadas. Atuaria, nesta lógica, sem chão histórico, apenas em função da vontade. (LIMA e MARTINS; 2005: 53)
\end{abstract}

Com efeito, esta ressignificação possibilita a sociedade civil ser assumida como o lugar privilegiado do diálogo, do "consenso", do empreendedorismo, da democracia, da criatividade, enquanto o Estado é relacionado com o ineficaz, com o burocrático (no sentido pejorativo), com o arcaico. Nestes processos se opera, também, um substancial esvaziamento do conceito de "sociedade civil", pois se retira do seu interior um determinante que, em Gramsci, é seu componente essencial: a luta de classes e o aspecto coercitivo inscrito nas relações sociais de produção, bem como a heteronomia dos aparelhos privados de hegemonia das classes fundamentais (burguesia e proletariado).

Apostando que os "novos atores sociais" que se proliferavam na sociedade civil nos últimos anos (movimentos de minorias, raça, etnia, gênero, sexualidade, etc.) seriam um claro esgotamento dos instrumentos da política tradicional (partidos, sindicatos e eleições, por exemplo), propõe-se uma política renovada, onde as relações sociais e políticas são marcadas pelo consenso, sendo, portanto, menos conflitivas, pois concebia o "diálogo como fundamento da lógica de conciliação (dos inconciliáveis) interesses de classes" (ibid.; 49). Para tanto, dever-se-ia estimular mecanismos de participação direta da sociedade civil no 


\section{Trabalhonecessário}

Issn: 1808 - 799X

ano 11, no 16 - 2013

aparelho estatal, incorporando as novas organizações, transformando-as em propulsoras desta sociabilidade.

Desta forma concebida, esta "repolitização da política", promove uma expansão dos direitos políticos ao mesmo tempo em que a esvazia conceitualmente. Pois busca retirar da política a sua dimensão conflitiva e valorizar a sua dimensão consensual e com isso, impedir qualquer possibilidade de alternativa ao capitalismo.

Diferenciando "grande política" de "pequena política", Gramsci afirma ser típicas da grande política as: questões ligadas às fundações de novos Estados e a luta pela defesa, conservação ou destruição de organismos econômico-sociais e suas estruturas. Em oposição, a "pequena política" seria a política do dia-a-dia, do cotidiano, das questões parciais que se apresentam no interior de uma estrutura. "Portanto, é grande política tentar excluir a grande política do âmbito interno da vida estatal e reduzir tudo a pequena política" (GRAMSCl; 2011: 243). A "repolitização da política" não é, portanto, uma estratégia recente das classes dominantes. Contudo, nesta conjuntura, esta operação tem um forte apelo, pois ecoa no malogro do bloco soviético, propugnados pelos teóricos da Terceira Via, como o fim do socialismo reforçando, por conseguinte, a inevitabilidade do capitalismo.

Também a "democracia" sofre um processo similar. Fontes (2011) afirma que a identificação da democracia com o ato exclusivo do sufrágio universalgrande traço identitário das democracias hodiernas - é um dos sintomas do esvaziamento político dela, que se basta agora em gerenciar as premissas do capitalismo. Evitar-se-ia, portanto, contestar o capitalismo em si, reduzindo tudo à "pequena política". Wood identifica o processo de esvaziamento político da democracia liberal ao longo de sua constituição histórica, com especial atenção à história da democracia americana, comparando-a a democracia grega, percebendo que nesta última o espaço democrático era um instrumento político

TrabalhoNecessário - www.uff.br/trabalhonecessario; Ano 11, № 16/2013. 


\section{Trabalhonecessário}

Issn: 1808 - 799X

ano 11, no $16-2013$

de contenção da exploração da maior parte pelos demais cidadãos- de fato, o governo da maioria contra uma minoria. Ao contrário, na democracia americana, quando não foi mais possível manter restrito às classes dominantes o conceito de povo (ou àqueles que gozam dos direitos políticos), buscou-se gradualmente, o esvaziamento dos mecanismos democráticos - haja vista o princípio da isegoria, ou seja, a conjunção entre "igualdade" e "liberdade de expressão", ter sido suprimido neste processo histórico. Ademais, substituiu-se um direito ativo (o da auto representação) por um direito passivo (o sufrágio universal). (WOOD; 2003).

Desta maneira, a pensadora inglesa afirma que a defesa do caráter público do Estado, da sua função social e, principalmente, da democracia, em seu sentido radical, são instrumentos importantes contra o capitalismo. Pois que o Estado é, em última análise, "o ponto decisivo de concentração de todo o poder na sociedade" (WOOD; 2003.:49). Fontes (op. cit.) ressalta algumas características que o Estado vem assumindo nas últimas décadas, em especial em sua função coercitiva à serviço da reprodução do que denomina de "capital-imperialismo". Diante aos problemas - de ordem planetária - colocados nos debates atuais pelo capitalismo (a degradação do meio- ambiente, o esgotamento dos recursos primários, a expropriação de povos, populações e recursos naturais nas diversas localidades do planeta, etc.), o Estado- Nação tem como atributo encapsular localmente o caráter da luta contra o capitalismo internacionalizado. Deve ser seletivo nas suas atribuições públicas, transferindo para setores da "sociedade civil" (aqui entendido, sobremaneira, como a iniciativa privada) as atribuições inerentes ao Estado. Isso sem falar na importância que os Estados - Nações continuam tendo como financiadores da indústria militar o que, segundo Mészáros, faz desta época a mais potencialmente fatal da história da humanidade. (MÉSZÁROS: 2009; FONTES: op. cit.). Pois esta readequação do Estado integral, agora sob forte hegemonia da Terceira Via, precisa cumprir o papel de conformar uma nova subjetividade e novos sujeitos políticos coletivos.

TrabalhoNecessário - www.uff.br/trabalhonecessario; Ano 11, № 16/2013. 


\section{Trabalhonecessário}

Issn: 1808 - 799X

ano 11, no $16-2013$

Isto posto, faz-se importante localizar historicamente a criação dos conselhos do FUNDEF-FUNDEB sob a influência da Terceira Via e qual papel lhe destina os intelectuais organizadores deste novo conformismo, que tiveram na reforma gerencial do governo FHC um momento axial.

\section{O governo FHC a Reforma Gerencial e os conselhos do FUNDEF.}

Desde o início do seu primeiro mandato, FHC cercou-se de intelectuais orgânicos afinados com a lógica da Terceira Via propagada pelos aparelhos dos Bancos Mundial (BM) e Interamericano de Desenvolvimento (BID). BresserPereira, um deles, fora escolhido para ocupar o Ministério da Administração Federal e Reforma do Estado (MARE). Seria responsável pela Reforma Gerencial do Estado Brasileiro. Não obstante o seu proeminente papel na execução da reforma, este intelectual orgânico ainda produziu uma série de análises e estudos que embasavam e defendiam a Reforma Gerencial.

Percorrendo o histórico político recente da República brasileira, BresserPereira (2002) entende que a crise do Estado no Brasil foi provocada por 15 longos anos de estagnação econômica, o aumento dos gastos públicos e por índices hiperinflacionários que somente foram revertidos a partir de 1994, com a criação do Plano Real. Esta crise teve como cerne a perda do crédito público (e sua consequente capacidade de intervenção) e pela sua poupança pública negativa. A crise do modo de intervenção, a falta de competitividade das empresas brasileiras no mercado global, o fracasso na constituição de um Estado de Bem Estar social, a crise na forma burocrática de administrar são todos fatores constituintes desta problemática, agravada pelo que denomina retrocesso burocrático representado pela Constituição de 1988, pois que comprometia ainda mais o Aparelho Federal em atribuições e gastos aos quais ele poderia (1) 


\section{Trabalhonecessário}

Issn: 1808 - 799X

ano 11, no $16-2013$

transferir aos entes federados; (2) contar com a participação da "sociedade civil". As propostas formuladas para o Estado brasileiro tinham como referências as reformas ocorridas principalmente no Reino Unido. Mais do que diminuir o tamanho do Estado, trata-se, de acordo com o intelectual, de redefini-lo: construir um "Estado menor, mas melhor" (ibidem.: 38). Esta redefiniçao terá como premissa a recuperação da sua governabilidade

Para isso a reforma do Estado teria de garantir um Estado sadio do ponto de vista fiscal, dotado de poupança pública que lhe permitisse desenvolver suas políticas, e administrativamente bem equipado, dotado de um serviço civil de profissionais e instituições adequadas para uma administração gerencial (BRESSER-PEREIRA; op. cit.: 38).

Seguindo o receituário das políticas macroeconômicas sistematizadas pelo FMI- Banco Mundial-BID, buscava-se afinar o Estado brasileiro a esta nova condição de concorrência globalizada, onde sua principal função continuaria sendo a de propulsor do desenvolvimento social e econômico, não mais como garantidor dos direitos sociais, mas principalmente como "sócio". Assim, cabia a esta Reforma Gerencial definir três esferas daquilo que estava sob sua responsabilidade. Primeiro aqueles serviços ou atribuições que poderiam ser atendidos com maior eficiência pelo mercado, em geral as empresas estatais. Isto significou um amplo leque de privatizações de empresas públicas ou de quebras de monopólios ${ }^{2}$. Do outro lado, aquelas funções que seriam o Núcleo Estratégico do Aparelho do Estado e deveria continuar sob esta estrutura, a Advocacia Geral da União e os cargos ligados à administração deste aparelho, por exemplo. Neste intermédio, estabelecem-se aquelas atribuições que, regulamentada e garantida pelo Estado, deveriam ser exercidos por organizações da sociedade civil: as organizações sociais. Nesta esfera se encontram a saúde, a educação, a previdência e a ciência e Tecnologia, todas elas devendo ser financiadas pelo

\footnotetext{
${ }^{2}$ Interessante é o caso da Petrobrás que poupada de ser privatizada, muito em conta por causa da reação popular, teve o seu monopólio sobre o Petróleo extinguido.
}

TrabalhoNecessário - www.uff.br/trabalhonecessario; Ano 11, № 16/2013. 


\section{Trabalhonecessário}

Issn: 1808 - 799X

ano 11, no $16-2013$

poder público (já que estes "serviços" são interesses de todos), mas não geridos pelo Estado: é a propriedade pública-não estatal. Nem propriedade privada (típica do mercado), nem propriedade estatal (típica do Estado), nem propriedade corporativa (típica dos sindicatos, associações e clubes), esta forma de propriedade demandaria outro tipo de organização para geri-la: as organizações sociais, que

Além de se constituir como espaço intermediário entre o Estado e o mercado, contribuindo para o fortalecimento das instituições democráticas, é mais eficiente e garante melhor qualidade para a realização destes serviços do que as organizações estatais ou privadas (ibidem: 235).

Propondo definir o "interesse público" com o vago "interesse comum a todos", os direitos sociais como "serviços sociais", os cidadãos como "usuários", e "publicização" como a transferência de direitos universais a gestão particular das organizações sociais que gozam de financiamento público (ou a parcerias públicoprivadas), a reforma gerencial do Estado brasileiro é promovida valorizando-se os princípios do mérito, da eficiência, do menor custo e melhor resultado, da satisfação do usuário, da desconcentração de atribuições, da descentralização de políticas públicas, da focalização das políticas sociais, e da redução de gastos do Estado, bem como do controle da sociedade sobre a execução destes serviços. Este controle se daria por quatro principais formas: o controle do legislativo, a opinião pública, as oposições politicas constituídas e, principal e diretamente: o controle social.

Com esta reforma, busca-se potencializar a promoção de uma sociabilidade ou conformismo que cada vez mais desresponsabilize o Estado em garantir os direitos sociais, abra espaço para a entrada do mercado no oferecimento destes direitos, estimule a participação responsável, transferindo para uma "sociedade" "proativa" atributos que seriam do Estado, sempre se 


\section{Trabalhonecessário}

Issn: 1808 - 799X

ano 11, no $16-2013$

mirando o consenso ou 0 acordo na manutenção dos imperativos macroeconômicos estabelecidos pelas agências financeiras mundiais.

Cabe afirmar que esta aproximação entre Gramsci e a realidade brasileira não é uma novidade. Outros períodos históricos brasileiros já foram analisados com base nesta matriz teoria, fazendo notar que o debate sobre a pertinência dos conceitos gramscianos para análise do Brasil, em especial do século $X X$ em diante, já foi positivamente superado. A aproximação do conceito de Revolução Passiva (quando o Estado assume o papel modernizante que deveria caber a uma determinada classe, fração ou conjunto de frações, utilizando-se para tanto o aparato coercitivo) já foi empreendida em períodos como o Estado Novo e a Ditadura Militar (COUTINHO, op. cit.).

O governo Lula da Silva tem sido também, por sua vez, objeto de aproximações com este arcabouço conceitual. Oliveira chama a atenção para o que denomina de "hegemonia às avessas": quando lideranças da classe subalterna põem-se a dirigir, de maneira até mais eficaz do que as frações burguesas, o projeto hegemônico destas últimas. Já Coutinho, prefere nominar o período do governo petista como o da "hegemonia da pequena política" onde teria sido retirado do debate político democrático qualquer alternativa ao sistema capitalista, bem como suas críticas radicais. Bianchi e Braga preferem caracterizar o período como de uma Revolução Passiva à brasileira. (OLIVEIRA, 2010).

Ademais as polêmicas de fundo existentes, e que não é do nosso escopo tratar, é possível perceber certo acordo entre estes diversos autores "gramscianos" brasileiros, sobre a permanência do transformismo como uma característica em todo este processo, seja na reforma gerencial no governo FHC, seja no governo seguinte de Lula da Silva. Pois que toda esta restruturação do aparelho do Estado não aconteceu e vem acontecendo sem (1) a absorção parcial das demandas populares, sem que isso atentasse contra a forma principal

TrabalhoNecessário - www.uff.br/trabalhonecessario; Ano 11, № 16/2013. 


\section{Trabalhonecessário}

Issn: 1808 - 799X

ano 11, no $16-2013$

de reprodução do capital, ao contrário, possibilitou uma ainda maior monopolização, internacionalização e financeirização da economia brasileira; (2) uma ampla cooptação de parcelas significativas e individuais de lideranças da classe trabalhadora e suas organizações, como a CUT (Central Única dos Trabalhadores) e o PT (Partido dos Trabalhadores) (FONTES, op. cit., OLIVEIRA, 2010).

Foi sob a égide da Reforma Gerencial que vimos surgir o Conselho de Acompanhamento e Controle Social do Fundo de Desenvolvimento do Ensino Fundamental e Valorização do Magistério (CACS-FUNDEF), precursor do Conselho de Acompanhamento e Controle Social do Fundo de Desenvolvimento do Ensino Básico e Valorização do Magistério (CACS-FUNDEB), reformulado pelo governo Lula da Silva cujo conjunto de leis nos ateremos mais pormenorizadamente.

\section{A legislação do CACS-FUNDEB}

A legislação relativa ao FUNDEB consiste em Emenda Constitucional, leis, portarias, decretos e resoluções diversas desde sua criação até os dias de hoje. Contudo, para a nossa análise, nos ateremos aquelas que instituem, normatizam, regulamentam e alteram o conselho em questão. Assim, elencamos como pertinentes, em nível federal, a lei 11.494/07 e a portaria do FNDE -430/08. Em nível municipal, procedemos à análise das seguintes leis: 2005/07; 2034/07 e 2080/08. No que diz respeito à composição do conselho, a lei 11.494, em seu Art. 24, determina que ele tenha, no mínimo, 9 membros, em nível municipal, sendo que apenas $2 \mathrm{com}$ vínculo direto ao Poder Executivo Municipal e os outros 7 representando ou a comunidade escolar ou a sociedade civil (relação Sociedade Política/ Sociedade Civil de 2/7). Em caso de existência tanto de Conselho 


\section{Trabalhonecessário}

Issn: 1808 - 799X

ano 11, no 16 - 2013

Municipal de Educação quanto de Conselho Tutelar, estes também tem direito à representação. Parece manifestar-se aí, ao menos no nível municipal, o objetivo de se superar as críticas feitas ao seu antecessor - o CACS-FUNDEF - que tinha caráter muito mais estatal do que social (DAVIES, op. cit.).

Ainda de acordo com esta lei, institui-se a maneira pela qual estes representantes serão indicados: ou por processo eletivo organizado para tanto (no caso de representantes dos pais, alunos e diretores, sendo omissa, no entanto, sobre de quem deveria ser a responsabilidade pela organização destas eleições) ou por sua respectiva entidade sindical (no caso de servidores e docentes). Também nela se definem as competências e atribuições do conselho, sendo as principais: acompanhar e exercer o controle social sobre a distribuição, a transferência e a aplicação dos recursos do Fundo; supervisionar o censo escolar e a elaboração da proposta orçamentária, formulando pareceres acerca da aplicação dos recursos, dentre outras.

Já a portaria 430/08 do FNDE cumpre um papel dúbio. Ao tempo que melhor especifica certos aspectos que na lei ordinária apareciam vagos ou eram omissos, em outros pontos dá indicações distintas daquelas presentes na lei maior. No primeiro caso temos, por exemplo, a especificação de que é o prefeito quem determina os ocupantes dos assentos designados ao poder executivo, ou mesmo a determinação da eleição de suplentes para todos os assentos. Faculta ao ente governamental local a possibilidade de criação de novos assentos, desde que respeitados os critérios apresentados (máximo de 2 assentos por segmento social ou instituição). Mas a portaria se torna imprecisa ou confusa quando se trata da forma de indicação dos representantes dos professores e servidores, pois atribui ao presidente da respectiva entidade sindical a indicação ao assento no conselho, ao tempo que diz que deve ser organizada eleição pra esta finalidade. Neste sentido, diverge do texto da lei 11.494, que atribui à entidade sindical a 


\section{Trabalhonecessário}

Issn: 1808 - 799X

ano 11, no $16-2013$

indicação do nome e não determina que esta deva ser feita pelo presidente da entidade.

Em nível municipal, analisamos principalmente as seguintes leis: 2005/07; 2034/07 e 2080/08. A primeira dispõe sobre a criação do conselho, ao passo que as outras duas promovem alterações naquela, em especial no que diz respeito à sua composição. Fazendo uso do poder que the é outorgado, o executivo municipal de Itaboraí cria o CACS-FUNDEB- Ita com 12 membros, através do Art. $2^{2}$ da lei 2005/07. Duas diferenças são sentidas nesta lei comparando-a a lei ordinária federal: primeiro a indicação de somente um assento ao poder executivo municipal, como também a presença de dois assentos reservados ao poder legislativo local. Contudo, nota-se a ausência dos artigos referentes à indicação dos representantes dos diversos segmentos sociais por intermédio de eleição organizada para tal fim, bem como a necessidade de indicação de suplentes.

Já a lei 2034/07 altera a lei anterior no seu Art 2º , o da composição, aumentando o número de representações do poder executivo municipal para 2 (dois) e o total de conselheiros para 13. Já a lei 2080/08 insere um parágrafo no artigo 5 da 2005/07 indicando a necessidade da indicação de um suplente por segmento social representado.

Os conselhos na educação podem combinar ou reunir três principais atribuições: a formulação política, a execução e a fiscalização. Ao conselho do FUNDEB cabe somente a fiscalização. No caso do FUNDEB o papel primordial é o de fiscalização. Esta atribuição reduzida fica mais alijada ao constatarmos que, pela lei, o caráter fiscalizador, tem mais caráter denunciador, pois o conselho não tem qualquer poder diferenciado de punição, sansão ou procedimento privilegiado. Deve recorrer, tal e qual o cidadão comum, ao Ministério Público, aos Tribunais de Conta ou ao poder legislativo do referido ente federativo.

Utilizar e disseminar mecanismos de participação concomitante ao processo onde esta participação é esvaziada de possibilidades parece ser uma

TrabalhoNecessário - www.uff.br/trabalhonecessario; Ano 11, № 16/2013. 


\section{Trabalhonecessário}

Issn: 1808 - 799X

ano 11, no 16 - 2013

sugestão que bem se encaixa aos conselhos. O reconhecimento das formas e dos conteúdos explícitos ou tácitos na construção da hegemonia e dos instrumentos utilizados pela burguesia para o apassivamento das classes subalternas são teorizações importantes para a prática transformadora. Destacado este perfil do conselho, permanece a pergunta: estes conselhos tem utilidade para os trabalhadores organizados em avanços de posição que modifiquem a seu favor a correlação de forças? É o que pretendemos responder na próxima sessão. Para tanto foram usadas metodologias como: análise de atas das reuniões, análise das planilhas apresentadas ao fundo, a pesquisa participante, e balanço bibliográfico, tendo como recorte temporal o ano de 2011 2012.

\section{O CACS- FUNDEB- Ita: participação “democrática”, legitimação do existente} vs. Iuta de classes.

O município de Itaboraí é situado na área metropolitana do Rio de Janeiro tendo uma extensão territorial de $429.3 \mathrm{Km}^{2}$ e uma população estimada de 211.000 habitantes. Suas principais atividades econômicas são serviços e comércio, transporte, construção civil, pecuária, apicultura, etc. Panorama econômico este que tem se modificado, tendo em vista que Itaboraí será sede da mais importante obra da indústria petroquímica no Brasil: o COMPERJ (Complexo Petroquímico do Rio de Janeiro).

As marcas principais da política local em Itaboraí são o clientelismo e o patrimonialismo. Na educação, isso não é diferente. A ausência de concursos públicos, por longos anos, remediado parcialmente com um concurso em 2011, para o provimento dos quadros técnicos administrativos nas escolas do município gera uma vacância, sendo estas vagas muitas vezes utilizadas como "cabide de 


\section{Trabalhonecessário}

Issn: 1808 - 799X

ano 11, no $16-2013$

emprego" dos vereadores para seus "cabos eleitorais". Isso acontece também, mas em menor escala, com relação aos docentes.

A sistematização das diversas formas de observação reforça a tese da incapacidade de um efetivo controle social, que dê cabo do mau uso do dinheiro público. Efetivamente, não há representação estudantil que nomeados - pelo poder público e não indicados pela entidade estudantil local - nunca se fizeram presentes na reunião; os servidores não têm seus representantes indicados por sua entidade; os representantes dos diretores de escolas- diretores estes que são indicados pelos vereadores e não escolhidos pela comunidade - poderão sofrer uma série de constrangimentos. Presidia as reuniões do CONFUNDEB-Ita, durante vasta parte do período estudado, um servidor publicamente lotado em cargo de confiança da Secretaria de Educação, mesmo mediante denúncia, pois proibido tanto pela 11494-2007 quanto pela legislação municipal. Seu afastamento em junho de 2012 se deu por conta da sua candidatura as eleições locais. Houve, ao longo de 2011, o pagamento durante diversos meses de serviços prestados por um Instituto local que goza de inúmeras denúncias de "caixa preta", mesmo que os serviços já estivessem notoriamente suspensos desde 0 ano anterior. Os balancetes contábeis de 2011 dispostos ao representante dos docentes iniciam-se no mês de março, faltando os dados referentes aos dois meses anteriores. Quatro balancetes de 2012 foram entregues atrasados (fevereiro-julho) em setembro e sem a assinatura do secretário de Fazenda, ou seja, sem qualquer valor legal. No ano de 2012, só foram apresentados os balancetes anteriores a agosto, sendo o restante não apresentado ao fundo.

As reuniões do conselho são, costumeiramente, formais, não estando os seus participantes aptos a desvendar planilhas e planilhas elaboradas por técnicos especializados, sem o devido auxílio. No que diz respeito à formação técnica dos conselheiros, não houve nenhum curso de formação oferecido pelo

TrabalhoNecessário - www.uff.br/trabalhonecessario; Ano 11, № 16/2013. 


\section{Trabalhonecessário}

Issn: 1808 - 799X

ano 11, no $16-2013$

MEC ou outros órgãos, desde o inicio da participação do conselheiro da entidade dos profissionais da educação (outubro de 2009) até hoje (novembro de 2012), embora haja a indicação de leituras de textos-manuais acerca do FUNDEB. $O$ acesso a documentos é sempre dificultado, mesmo para os conselheiros, em flagrante contradição com as diversas leis (federal e municipal) que obrigam o poder público a disporem de balancetes de forma permanente a seus conselheiros e determina a disposição de cópias de todos os documentos que o conselheiro acreditar ser importante para o exercício de sua função. As atas das reuniões do conselho no período de 2011-2012 repetidas vezes requisitadas pelo representante dos docentes, só foram dispostas após o afastamento do então Presidente (junho-2012). A receita Municipal não é tornada pública na reunião do conselho que tem os dados tão somente das receitas advindas do governo federal, impedindo um mapeamento mais abrangente- e menos impreciso- das receitas totais da educação. Mesmo com concursos públicos em vigência, professores e funcionários continuam sendo contratados de forma terceirizada e temporária. Conclui-se, dessa maneira, que o CACS FUNDEB-ita não consegue dar cabo do uso privado da educação e dos seus recursos e, no caso de Itaboraí, o uso clientelista e patrimonialista da SEMEC.

Destaca-se um ponto: o CACS FUNDEB, para além dos problemas supracitados, aprofunda, neste sentido, o esvaziamento do caráter transformador da democracia, ao delegar a um representante a tarefa de discutir tão somente a pequena política, seja reduzindo as atribuições do conselho à fiscalização, seja não dando condições técnicas para os conselheiros exercerem suas funções. Reproduz, em sua escala, a "repolitização" da política e da democracia, ao delegar ao conselho a tarefa de acompanhamento, sem instrumentalizar os conselheiros para ela. Desta maneira, afasta-se aqui, como pertinentes, sugestões como atribuir ao Estado a responsabilidade de organizar estes espaços para que se tornem realmente democráticos e plurais de articulação e 


\section{Trabalhonecessário}

Issn: 1808 - 799X

ano 11, no $16-2013$

participação. Ou mesmo que a participação social nos conselhos de acompanhamento e controle, ademais as dificuldades, são, per si, um exercício e um aprendizado de participação social (BARBOSA, 2006). Mas, com isso, não se quer negar o caráter contraditório dos conselhos ou, melhor dizendo, a possibilidade de o conselho auxiliar os trabalhadores na construção de uma hegemonia distinta e na a construção de uma correlação de forças menos desfavorável. Partindo de Davies que, analisando o conselho e o papel dos profissionais da educação neste processo, afirma:

\footnotetext{
[o limite da ação fiscalizadora] é maior quando se considera que os órgãos responsáveis pela fiscalização (basicamente os Tribunais de Contas) não são plenamente confiáveis para essa tarefa, o que impõe o desafio do controle social sobre o uso de verbas das verbas da educação, algo que os Conselhos do FUNDEF não resolveram, sendo muito pouco provável que os do FUNDEB sejam bem sucedidos, a não ser que a sociedade $e$, em especial, os profissionais da educação básica se organizem, mobilizem e adquiram uma formação adequada para este controle social. (grifos meu). (DAVIES; 2007: 56)
}

Entendendo que o conselho em questão lida com a problemática do financiamento, a natureza das conquistas auferidas pela participação neste conselho são, predominantemente, de ordem econômica. Portanto, logo de início, aproximamos da nossa perspectiva a afirmativa de Gouveia e Souza (2006) que, abordando os conselhos do FUNDEF afirmam que se eles não cumpriram o seu papel técnico, ao menos serviram para centenas de pessoas discutirem os seus limites, publicitarem estas denúncias e manterem vivo na agenda política o debate sobre financiamento da educação. Isto posto, interessa-nos, sobremaneira, as conquistas desta ordem obtidas pelos trabalhadores da educação neste período.

No que diz respeito aos salários dos profissionais da educação, a tabela I (anexo) demonstra a evolução deste desde jan/2010 até jan/2012. A tabela aqui reproduzida é apenas uma parcial (por economia de espaço) de uma tabela maior produzida pelo Departamento Intersindical de Estudos Socioeconômicos (DIEESE) ao sindicato local, que avalia a evolução salarial tendo como base o 


\section{Trabalhonecessário}

Issn: 1808 - 799X

ano 11, no 16 - 2013

piso salarial de maio de 1998 (1ํ ano do FUNDEF) e a inflação acumulada no período (utilizando-se dois índices: DIEESE e IBGE), tentando analisar se os reajustes concedidos significam ganhos reais (para além do índice inflacionário acumulado) ou não. A tabela apresentada ressalta, portanto, que os ganhos obtidos nos últimos anos foram fundamentais para os trabalhadores obterem um aumento acima da inflação, comparando janeiro de 2012 com maio de 1998. Percebe-se que no início de cada ano (2010-2011-2012) houve reajustes nos vencimentos destes. O último reajuste antes de 2010 tinha sido um de 5\% ainda em junho de 2006. Aqui, duas observações são importantes, primeiro sobre o alto índice de reajuste em janeiro de 2012 (81,5\%). Este dado deve ser decomposto em dois fatores: o reajuste de $10 \%$ no referido mês e a incorporação da regência ao piso - recebido sob a forma de abono- elevando o piso salarial que é o referencial utilizado pelo Departamento Intersindical de Estudos Socioeconômicos (DIEESE) para a composição de seus cálculos. Outro avanço que se faz registro foi a conquista da data-base para a categoria, bem como o início da discussão de um novo Plano de Cargos Carreiras e Salários que garantissem a progressão da carreira em vista do grande aporte de recursos que o município terá por conta do COMPERJ. Neste sentido, os trabalhadores da educação conseguiram uma mudança na correlação de forças a seu favor.

Segundo, é relembrar que os docentes assumiram assento no conselho em outubro de 2009, não sendo mera coincidência o período entre a assunção do assento e as conquistas salariais. Neste sentido, e ainda que endógena, a presença do conselho de fiscalização, mesmo em uma atribuição tão limitada, ajuda a desenvolver uma prática salutar na defesa da res publica. Pode ser, portanto, um importante passo no que diz respeito à superação das práticas clientelistas e fisiológicas tão arraigadas naquele município. No caso dos professores, objeto de análise em questão, isso se consubstanciou em conquistas reais de valorização e nestas, foram importantes os dados disponibilizados pela 


\section{Trabalhonecessário}

Issn: 1808 - 799X

ano 11, no $16-2013$

participação no conselho, pois, mesmo que insuficientes e parciais, contribuíram para uma ação política com maior incidência na realidade. Conclui-se assim que, sob determinadas condições conjunturais, a participação de entidades dos trabalhadores da educação nestes conselhos podem potencializar a ação na luta por conquistas materiais para estes, como também ser importante expediente no democrático e necessário combate ao mau uso da verba pública. Não sem contradição, pois ao mesmo tempo promove uma valorização de uma participação "responsável" que busque sempre soluções conciliadas, desprezando as diferenças de poder das distintas classes e grupos sociais.

Cabe, contudo, a estas entidades de classe ou populares (profissionais da educação, estudantes da rede pública e pais de alunos), em especial aquelas comprometidas com uma profunda transformação socioeconômica, utilizarem-se, quando possível, destes espaços a fim de instrumentalizarem a luta por outra escola pública. Esta que só pode ser realizada no interior da luta por outra sociedade e outro conformismo, onde a participação democrática, politizada e coletiva, não individualista, possa produzir uma sociabilidade dialética àquela afirmada na constituição desta forma de conselho: pois embora oposta, objetiva a superação. A apropriação dialética dos conselhos podem auxiliar aos trabalhadores na sua urgente tarefa de dar relevância à dimensão conflitiva da democracia, afinal somente o conflito possibilita a luta de classes. Esta seria uma maneira pela qual a democracia poderia deixar de ser mera formalidade e voltar a ter tonalidades do seu teor transformador (WOOD, op. cit.). 


\section{Trabalhonecessário}

Issn: 1808 - 799X

ano 11, no $16-2013$

\section{Anexo: Tabela I}

\begin{tabular}{|c|c|c|c|c|c|c|c|c|c|c|}
\hline & & tegoria: & PE - 1 & orai & & & & & & \\
\hline & & & rofissionais & ucação da & de Municip & Ee Ensino d & aborai & & & \\
\hline & & ta-Base: & & & & & & & & \\
\hline & & & & & & & & & 01-mai-98 = & $00)$ \\
\hline Mês/Ano & Salári & minal & $\mathrm{ICV}$ & & Salário & Perda & $\mathrm{INP}$ & & Salário & Perda \\
\hline & Reajuste & Índice & Mensal & Índice & Real & Mensal & Mensal & Índice & Real & Mensal \\
\hline jan-10 & $10,00 \%$ & 170,78 & $1,72 \%$ & 214,23 & 79,72 & $-20,28 \%$ & $0,88 \%$ & 213,57 & 79,96 & $-20,04 \%$ \\
\hline fev-10 & $0,00 \%$ & 170,78 & $0,59 \%$ & 215,50 & 79,25 & $-20,75 \%$ & $0,70 \%$ & 215,07 & 79,41 & $-20,59 \%$ \\
\hline mar-10 & $0,00 \%$ & 170,78 & $0,47 \%$ & 216,52 & 78,88 & $-21,12 \%$ & $0,71 \%$ & 216,59 & 78,85 & $-21,15 \%$ \\
\hline$a b r-10$ & $0,00 \%$ & 170,78 & $0,22 \%$ & 217,00 & 78,70 & $-21,30 \%$ & $0,73 \%$ & 218,18 & 78,28 & $-21,72 \%$ \\
\hline mai-10 & $0,00 \%$ & 170,78 & $0,15 \%$ & 217,34 & 78,58 & $-21,42 \%$ & $0,43 \%$ & 219,11 & 77,94 & $-22,06 \%$ \\
\hline jun-10 & $0,00 \%$ & 170,78 & $0,02 \%$ & 217,38 & 78,56 & $-21,44 \%$ & $-0,11 \%$ & 218,87 & 78,03 & $-21,97 \%$ \\
\hline jul-10 & $0,00 \%$ & 170,78 & $0,14 \%$ & 217,68 & 78,45 & $-21,55 \%$ & $-0,07 \%$ & 218,72 & 78,08 & $-21,92 \%$ \\
\hline ago-10 & $0,00 \%$ & 170,78 & $0,25 \%$ & 218,23 & 78,26 & $-21,74 \%$ & $-0,07 \%$ & 218,57 & 78,14 & $-21,86 \%$ \\
\hline set-10 & $0,00 \%$ & 170,78 & $0,53 \%$ & 219,38 & 77,85 & $-22,15 \%$ & $0,54 \%$ & 219,75 & 77,72 & $-22,28 \%$ \\
\hline out-10 & $0,00 \%$ & 170,78 & $0,93 \%$ & 221,43 & 77,13 & $-22,87 \%$ & $0,92 \%$ & 221,77 & 77,01 & $-22,99 \%$ \\
\hline nov-10 & $0,00 \%$ & 170,78 & $1,04 \%$ & 223,72 & 76,34 & $-23,66 \%$ & $1,03 \%$ & 224,05 & 76,22 & $-23,78 \%$ \\
\hline $\operatorname{dez}-10$ & $0,00 \%$ & 170,78 & $0,65 \%$ & 225,17 & 75,85 & $-24,15 \%$ & $0,60 \%$ & 225,40 & 75,77 & $-24,23 \%$ \\
\hline jan-11 & $8,00 \%$ & 184,44 & $1,28 \%$ & 228,06 & 80,88 & $-19,12 \%$ & $0,94 \%$ & 227,52 & 81,07 & $-18,93 \%$ \\
\hline fev-11 & $0,00 \%$ & 184,44 & $0,41 \%$ & 228,99 & 80,55 & $-19,45 \%$ & $0,54 \%$ & 228,74 & 80,63 & $-19,37 \%$ \\
\hline mar-11 & $0,00 \%$ & 184,44 & $0,91 \%$ & 231,07 & 79,82 & $-20,18 \%$ & $0,66 \%$ & 230,25 & 80,10 & $-19,90 \%$ \\
\hline$a b r-11$ & $0,00 \%$ & 184,44 & $0,80 \%$ & 232,91 & 79,19 & $-20,81 \%$ & $0,72 \%$ & 231,91 & 79,53 & $-20,47 \%$ \\
\hline mai-11 & $0,00 \%$ & 184,44 & $0,04 \%$ & 233,01 & 79,16 & $-20,84 \%$ & $0,57 \%$ & 233,23 & 79,08 & $-20,92 \%$ \\
\hline jun-11 & $0,00 \%$ & 184,44 & $-0,34 \%$ & 232,22 & 79,43 & $-20,57 \%$ & $0,22 \%$ & 233,75 & 78,91 & $-21,09 \%$ \\
\hline jul-11 & $0,00 \%$ & 184,44 & $0,44 \%$ & 233,23 & 79,08 & $-20,92 \%$ & $0,00 \%$ & 233,75 & 78,91 & $-21,09 \%$ \\
\hline aga-11 & $0,00 \%$ & 184,44 & $0,39 \%$ & 234,13 & 78,78 & $-21,22 \%$ & $0,42 \%$ & 234,73 & 78,58 & $-21,42 \%$ \\
\hline set-11 & $0,00 \%$ & 184,44 & $0,69 \%$ & 235,74 & 78,24 & $-21,76 \%$ & $0,45 \%$ & 235,79 & 78,23 & $-21,77 \%$ \\
\hline out-11 & $0,00 \%$ & 184,44 & $0,31 \%$ & 236,46 & 78,00 & $-22,00 \%$ & $0,32 \%$ & 236,54 & 77,98 & $-22,02 \%$ \\
\hline nov-11 & $0,00 \%$ & 184,44 & $0,52 \%$ & 237,69 & 77,60 & $-22,40 \%$ & $0,57 \%$ & 237,89 & 77,53 & $-22,47 \%$ \\
\hline $\operatorname{dez} z-11$ & $0,00 \%$ & 184,44 & $0,50 \%$ & 238,87 & 77,21 & $-22,79 \%$ & $0,51 \%$ & 239,10 & 77,14 & $-22,86 \%$ \\
\hline jan-12 & $81,50 \%$ & 334,77 & $1,32 \%$ & 242,02 & 138,32 & Ganho & $0,51 \%$ & 240,32 & 139,30 & Ganho \\
\hline Reajuste & & & & & & & & & & \\
\hline Ne cessári & 1 de fever & & & Há ga & $38,32 \%$ & & & Há gar & $39,30 \%$ & \\
\hline
\end{tabular}

Fonte: DIEESE

TrabalhoNecessário - www.uff.br/trabalhonecessario; Ano 11, № 16/2013. 


\section{Trabalhonecessário}

Issn: 1808 - 799X

ano 11, no $16-2013$

\section{Bibliografia:}

BARBOSA, Selma Maquiné; Conselho do FUNDEF: participação social possível?; IN: SOUZA, Donaldo Bello de (org.) et all; Acompanhamento e controle social da educação- Fundos e programas federais e seus conselhos locais; São Paulo; ed. Xamã; págs.;159-75; 2006.

BRESSER-PEREIRA; Luiz Carlos; Reforma do Estado para a cidadania: a reforma gerencial brasileira na perspectiva nacional; São Paulo; Ed. 34; Brasília; ENAP; 2002.

COUTINHO; Carlos Nelson; Gramsci: Um estudo sobre o seu pensamento político; 3ํㅗㄹ ed.; Rio de Janeiro; Ed. Civilização Brasileira; 2007.

DAVIES, Nicholas.; FUNDEB: a redenção da educação básica?; Niterói; 2007.

FONTES, Virgínia; Brasil e o capital imperialismo; Rio de Janeiro; EdUFRJ; FioCruz; 2011.

GRAMSCI, A; O leitor de Gramsci: escritos escolhidos 1916- 1935; (org.) Carlos Nelson Coutinho; Rio de Janeiro; Civilização Brasileira; 2011.

; Cadernos do Cárcere- volume -1; (Org.) Carlos Nelson Coutinho; 4ª edição; Rio de Janeiro; Civilização Brasileira; 2006.

GOUVEA, Andréa Barbosa; SOUZA, Ângelo Ricardo; Revisitando a questão da natureza e da prática dos Conselhos de Acompanhamento e Controle Social (cacs) do FUNDEF no estado do Paraná; IN: SOUZA, Donaldo Bello de (org.) et all; Acompanhamento e controle social da educação- Fundos e programas federais e seus conselhos locais; São Paulo; ed. Xamã; págs.;137-58; 2006.

HAYEK, Friedrich A. Os princípios de uma ordem social liberal; IN: Ideologias Políticas. Tradução e revisão de Sérgio Duarte. Campinas; Editora UNB, 1999.

LÊNIN, Vladimir I.; O Estado e a Revolução; São Paulo; Ed. Expressão Popular; 2007.

TrabalhoNecessário - www.uff.br/trabalhonecessario; Ano 11, № 16/2013. 


\section{Trabalhonecessário}

Issn: 1808 - 799X

ano 11, no $16-2013$

; O imperialismo - Etapa superior do capitalismo; Disponível em: http://pcb.org.br/portal/docs/oimperialismo.pdf Acessado em: 05-11-2012. LIMA e MARTINS, K.R e A.S.; Pressupostos, princípios e estratégias; IN: A nova Pedagogia da hegemonia- Estratégias do Capital para educar o consenso/ Lúcia Maria Wanderley Neves (org.) - São Paulo; Ed. Xamã, 2005.

OLIVEIRA, Francisco de (org.); Hegemonia às Avessas; São Paulo; Ed. Ed. Boitempo; 2010.

MELO, Adriana Almeida Sales de; Os organismos internacionais na condução de um novo bloco histórico; IN: A nova Pedagogia da hegemonia- Estratégias do Capital para educar o consenso/ Lúcia Maria Wanderley Neves (org.) - São Paulo; Ed. Xamã, 2005.

MÉSZÁROS, O século XXI- socialismo ou barbárie? São Paulo; Ed. Boitempo; 2009.

SOUZA, Donaldo Bello de (org.) et all; Acompanhamento e controle social da educação- Fundos e programas federais e seus conselhos locais; São Paulo; ed. Xamã; 2006.

WOODS; Ellen Meskins; Democracia contra o capitalismo- a renovação do materialismo histórico; São Paulo: Boitempo, 2003.

Data de recebimento: 05/02/2013

Data de aprovação: 27/02/2013 